\title{
Procesos fundacionales. Huellas y sentidos de un espacio institucional: El Servicio Educativo.
}

Susana Celman (1)

Hace mucho tiempo que los pedagogos sostenemos que las instituciones se conforman por procesos complejos, heterogéneos, planificados y azarosos. Que en ellos los sujetos y las relaciones interpersonales se entrecruzan con dimensiones sociales, políticas y, especialmente en este caso, educativas, que nos permiten aventurar, años más tarde, los sentidos posibles de algunas líneas de acción de esos emprendimientos colectivos.

Este texto no tiene una intención enumerativa de lo hecho en el Área del Servicio Educativo, dado que solo retomaré dos ejes dentro de los que orientaron nuestro trabajo allí. Tampoco lo impregna un sentimiento de nostalgia por un pasado presentado como modélico. Estoy convencida de que recuperar los itinerarios construidos es una magnífica oportunidad para reflexionar sobre los modos en que grupos de sujetos en condiciones particulares, aportaron a un proyecto común.
(1) Ex integrante del servicio educativo de la FHUC. 
Me acerqué a esta institución en 1987, de la mano de Mauricio Epelbaun, desde Paraná, desde mi formación en Ciencias de la Educación, desde mi apasionado deseo de aportar a la reconstrucción de la Universidad Pública desvastada por la dictadura militar.

Me encontré con un espacio altamente motivador y con un grupo que perseguía un objetivo: Había que "normalizar" la Escuela y transformarla en Facultad.

Este propósito, alejado de intereses sectoriales, se relacionaba fuertemente con una intencionalidad académica de más alto vuelo: ubicar a las ciencias que tratan las problemáticas de la educación y, más específicamente, de la enseñanza, de la formación docente, en el mismo plano que la Universidad Nacional del Litoral le había otorgado a las "otras ciencias". Creo que se estaba librando una lucha epistemológica y de posicionamiento en el campo de los estudios universitarios. Dejar de ser "la escuela" para constituirse en "una Facultad más de la UNL", significaba poner al descubierto imaginarios, convicciones e ideologías que generaron un clima de estudio, producciones, polémicas y confrontaciones tanto al interior de la propia institución cuanto en el escenario amplio de la universidad.

En 1987 se crea el Área de Servicio Educativo, un nuevo espacio pensado con funciones de colaboración con los equipos docentes, alumnos y egresados de la nueva facultad. Respecto de los primeros se proponía trabajar con los profesores a partir de las problemáticas en sus prácticas concretas, analizar diferentes marcos teóricos y organizar el intercambio de experiencias educativas con otras facultades y carreras de formación docente. Con relación a los egresados se atribuía a esta área la función de establecer con ellos formas orgánicas de comunicación a fin de recuperar sus experiencias laborales como aporte a la educación de los nuevos estudiantes y a la vez, poder organizar actividades de formación y capacitación con los egresados de las distintas carreras. Por último, con relación a los estudiantes, prevé la necesidad de conocer a los que ingresan y apoyarlos en su incorporación a los estudios universitarios. Finalmente, considera la necesidad de crear y mantener contactos con organismos educativos de la provincia a fin de posibilitar trabajos de campo y extensión, y favorecer la creación de equipos de investigación conjuntamente con esta área, para abordar problemáticas propias del campo de la educación. 
Para encarar el desafío de comenzar una tarea sistemática y orgánica en tal sentido, conformamos un grupo de trabajo con las Profs. Nélida Barbach y Martha Bolsi, entre otras. Recuerdo nuestras primeras reuniones en las que discutíamos "por dónde empezar", nuestros borradores que intentaban plasmar las primeras líneas de acción, las discusiones con Mauricio y su ímpetu por provocar el cambio.

Hoy, al volver a mirar y reflexionar sobre aquellos momentos, me parece vislumbrar que las diferentes iniciativas que se fueron gestando tenían, al menos, dos ejes fuertes que traducían los acuerdos básicos entre nosotros: en primer lugar, que era necesario analizar y poner en discusión las concepciones y las prácticas educativas habituales que los profesores ejercían en las diferentes carreras y en segundo lugar, que había que intentar realizar cambios curriculares significativos, problemáticas que para nuestras perspectivas, estaban fuertemente interrelacionadas. También sabíamos que esto solo era posible con el consenso de los colegas docentes y los estudiantes.

Se implementó, así, un Programa de Formación y Actualización Docente mediante el desarrollo de cursos de Epistemología, Metodología de la Investigación, Currículum, Pedagogía Universitaria, Didáctica, Instituciones educativas, etc. con destacados especialistas (F. Schuster, G. Guariglia, M. Saleme, Ma. T. Sirvent, O. Menin, G. Carbone, L. Fernández, entre otros). Desde la coordinación del Servicio Educativo, la propuesta era provocar, a partir de estos marcos teóricos referenciales, nuevas miradas sobre las propuestas pedagógicas y ponerlas en tensión con enfoques que eran objeto de debate en las Facultades que incluían carreras propias del campo de la educación superior. En este mismo sentido, se organizaron los primeros cursos para estudiantes y jóvenes egresados con la finalidad de transitar con ellos los primeros pasos en su proceso de iniciación a la docencia. Esto tenía que ver con la idea de transformar la cátedra unipersonal en equipos que asumieran la responsabilidad de la enseñanza tal como es habitual en el ámbito universitario.

El segundo eje que aunó el trabajo de los que integrábamos el Área de Servicio Educativo, tuvo que ver con el complejo proceso de transformación curricular, iniciado desde Secretaría Académica en 1990. 
Existían ya en esta institución carreras orientadas a la formación docente en las áreas de Historia, Biología, Geografía, Matemática y Lengua, pero era necesario revisar sus contenidos y sus propuestas pedagógicas a fin de sostener la necesidad, desde lo académico-disciplinar de transformar la Escuela en Facultad. Esto implicaba además, abrir el debate sobre posibles licenciaturas y recuperar para esta institución los modos de relación propios del quehacer universitario articulando docencia, investigación y extensión.

Pensar el cambio como una tarea colectiva significó analizar y discutir estrategias de involucramiento y participación. Se organizaron así grupos de trabajo interdisciplinarios con profesores integrantes de los diferentes departamentos. También, por disciplinas y por año.

Recuperar el pasado solo tiene sentido si nos permite reconocer en esas huellas algunas marcas identitarias de las instituciones en la actualidad y desde ahí, quizás, seguir pensando el futuro. Sostengo que las identidades tienen que ver con los momentos fundacionales, los sujetos que en ella se involucraron y los imaginarios colectivos desde los cuales diseñaron un proyecto.

Hoy la Facultad de Humanidades y Ciencias tiene algo que ver con la vieja Escuela pero también con los directivos y docentes que creyeron que valía la pena asumir el riesgo de la disputa para refundar sentidos en el contexto de la Universidad del Litoral. Queda aún y siempre la hermosa posibilidad de seguir pensando y otorgar nuevos sentidos a los procesos de la Formación en el campo de las Humanidades y las Ciencias que devengan de las tensiones y relaciones propias de la academia, así como del diálogo de ésta con la sociedad. 